\title{
Avaliacão de diferentes concentrações dos meios de cultura MS e Knudson para propagação in vitro da bromélia-imperial ${ }^{1}$
}

\author{
VANESSA COELHO NAVES ${ }^{2}$, PATRÍCIA DUARTE DE OLIVEIRA PAIVA ${ }^{3}$, RENATO PAIVA ${ }^{4}$, \\ MOACIR PASQUAL ${ }^{3}$ e LUCIANO VILELA PAIVA ${ }^{5}$
}

\begin{abstract}
RESUMO
A propagação de bromélias por meio da cultura de tecidos tem tido grande importância. Mediante a produção de mudas em larga escala, é possível atender aos mercados nacional e internacional e, ainda, permitir a produção de exemplares para programas de reintrodução em habitats quando se trata de espécies ameaçadas de extinção. Para esse processo, a definição do tipo de meio de cultura e concentração a utilizar é bastante relevante, permitindo determinar um protocolo eficiente e economicamente viável para propagação da cultura. Objetivou-se, neste trabalho, avaliar o comportamento de plântulas de bromélia-imperial (Alcantarea imperialis) em diferentes concentrações do meio de cultura MS (50 e $150 \%$ da sua concentração original) e do meio Knudson (50 e $150 \%$ da concentração original), tendo como testemunha a concentração original dos meios $(100 \%)$. A todos os meios, acrescentaram-se $2 \mathrm{mg} . \mathrm{L}^{-1}$ de thidiazuron (TDZ), 30 g.L. $\mathrm{L}^{-1}$ de sacarose e 7 g.L. $\mathrm{L}^{-1}$ de ágar. Após 120 dias, realizaram-se as avaliações. Os parâmetros analisados foram os seguintes: número de explantes responsivos, número de brotações por explante, altura de brotos e intumescimento. $\mathrm{O}$ meio MS na sua concentração original (100\%) proporcionou os melhores resultados.
\end{abstract}

Palavras-chave: Bromeliaceae, meios de cultura, propagação in vitro, Alcantarea imperialis.

\section{ABSTRACT \\ Evaluation of different concentrations of MS and Knudson culture media for the in vitro propagation of imperial bromeliad}

The propagation of bromeliads using tissue culture has received considerable importance. Through the plant production in large scale it is possible to attend both national and international consumers as well as programs for the reintroduction of species in their habitats especially those considered endangered. For this process, the definition of the type of culture medium and the concentration to be used is very important to determine an efficient and economical protocol for propagation of a species. The objective of this work was to evaluate the behavior of imperial bromeliad (Alcantarea imperialis) plantlets in different concentrations of MS (50 and 150\% of the original concentration) and Knudson (50 and $150 \%$ of the original concentration) media using as control their original concentration $(100 \%)$. All media were supplemented with $2 \mathrm{mg} \mathrm{L}^{-1}$ thidiazuron (TDZ), 30 g.L - $^{-1}$ sucrose and 7 g.L. ${ }^{-1}$ agar. Number of responsive explants, shoot number per explant, shoot height and swelling were evaluated 120 days after inoculation. It was observed that the use of $100 \%$ MS medium provided the best results.

Key words: Bromeliaceae, culture medium, in vitro propagation, Alcantarea imperialis.

\footnotetext{
${ }^{1}$ Parte da dissertação de mestrado da primeira autora.

${ }^{2}$ Mestre em Fitotecnia, Universidade Federal de Lavras (UFLA) 37200-000 Lavras (MG).

${ }^{3}$ Departamento de Agricultura, UFLA. E-mail: pdolivei@ufla.br

${ }^{4}$ Departamento de Biologia, UFLA.

${ }^{5}$ Departamento de Química, UFLA.
} 


\section{INTRODUÇÃO}

As bromeliáceas são plantas que impressionam pelas formas exóticas e pela ampla gama de cores e variedade das flores e folhas. Possuem grande valor para arranjos e vasos de interior e ocupam sempre lugar de destaque em projetos paisagísticos.

Além da importância ornamental, as bromélias representam valioso papel na ecologia de vários ambientes, servindo como alimento e local de proteção para muitos animais, atuando como reservatórios de água em ambientes mais secos e, pela decomposição de suas folhas, proporcionando formação de solo viável para sobrevivência de espécies vegetais mais exigentes (LEME \& MARIGO, 1993; OLIVEIRA et al., 1994).

A falta de informações específicas sobre técnicas de propagação e cultivo tem desestimulado a produção de bromélias, sendo, muitas vezes, as espécies oferecidas para comercialização provenientes de extrativismo (MELO, 1996). Em muitos casos, tais espécies são retiradas de populações com poucos representantes, como a Alcantarea imperialis (Carrière) Harms, que ocorre em campos de altitude e, por ser amplamente utilizada em projetos paisagísticos, vem sendo alvo do extrativismo. Apesar de produzir sementes em abundância e com alta viabilidade, não é capaz de emitir brotações laterais, como a maioria das plantas dessa família.

$\mathrm{Na}$ natureza, assim como em pequenos viveiros onde são cultivadas, as bromélias se propagam bem por meio de sementes, pois, geralmente, produzem grande quantidade dessas estruturas (RAUH, 1990; DOSOLTO 2001). Esse tipo de propagação, porém, é muito lento. Algumas espécies, entre elas a Alcantarea imperialis, podem levar até cinqüenta anos para atingir a idade adulta em seu ambiente natural (LEME \& MARIGO, 1993).

Outra maneira comum de propagação é mediante a emissão de brotações laterais ou afilhos, uma forma natural de propagação vegetativa, comum entre as bromélias (CÂNDIDO, 1996). No entanto, o número dessas brotações produzidas por planta é geralmente pequeno, não sendo suficiente para suprir o mercado crescente.

A utilização da técnica de cultura de tecidos é uma importante forma de propagação, possibilitando a produção de plantas em larga escala, num período reduzido de tempo, e maior uniformidade e qualidade das mudas em relação aos métodos convencionais. Pela produção massal de bromélias, é possível produzir mudas para reintrodução em habitats e, ainda, comercializar (mercado interno e externo), coibindo práticas extrativistas (ZORNING, 1996; NUNES \& FORZZA, 1998), pois a taxa de multiplicação de bromélias in vitro é geralmente muito superior àquela conseguida in vivo (MERCIER \& KERBAUY, 1995).

O meio MS tem sido utilizado para propagação de algumas espécies de bromélias - Aechmea fasciata e Guzmania ssp. (PIERIK et al., 1984); Tillandsia cyanea (PIERIK \& SPRENKELS, 1988), Aechmea victoriana e A. dactylina (DIJCK et al., 1988), Neoregelia carolinae (TOMBOLATO et al., 1991).

O meio Knudson, desenvolvido em 1946 para propagação de sementes de orquídeas (GEORGE, 1996), também foi testado para propagação de bromélias, como Vriesea fosteriana e $V$. hieroglyphica (MERCIER \& KERBAUY, 1992, 1994, 1995). Para a micropropagação de Alcantarea imperialis, no entanto, nenhum registro foi encontrado.

Assim, objetivou-se avaliar a multiplicação in vitro de explantes da bromélia-imperial (Alcantarea imperialis), cultivados em diferentes concentrações dos meios de cultura MS e Knudson, a fim de determinar o meio mais adequado a sua propagação.

\section{MATERIAL E MÉTODOS}

As plântulas de Alcantarea imperialis já se encontravam estabelecidas in vitro e foram obtidas de sementes.

No experimento, avaliou-se o desenvolvimento de Alcantarea imperialis cultivada em três concentrações do meio MS (MURASHIGE \& SKOOG, 1962): 50\%, $100 \%$ (concentração original, testemunha) e $150 \%$ e três concentrações do meio Knudson modificado: $50 \%$, $100 \%$ e $150 \%$. Os meios foram diluídos ou concentrados a partir da sua composição original, alterando tanto a concentração de sais como de orgânicos. Em todos os tratamentos, adicionou-se thidiazuron (TDZ) na concentração $0,02 \mathrm{mg} \cdot \mathrm{L}^{-1}$, conforme NAVES \& PINTO (1996) e $7 \mathrm{~g} . \mathrm{L}^{-1}$ de ágar. Os meios foram distribuídos em tubos de ensaio contendo $20 \mathrm{ml}$ de meio em cada um, e, o $\mathrm{pH}$, ajustado para 5,8 antes do processo de autoclavagem realizado a $121^{\circ} \mathrm{C}, 1 \mathrm{~atm}$. por 20 minutos.

Em cada tubo de ensaio, colocou-se um explante, com as folhas e raízes cortadas, permanecendo apenas 
as folhas mais jovens e o caule contendo as gemas axilares. Após a inoculação, os explantes foram mantidos em sala de crescimento com fotoperíodo de 16 horas sob luz branca fria, complementada com lâmpada Grolux, irradiância de $56 \mu \mathrm{mol} \cdot \mathrm{m}^{-2} \cdot \mathrm{s}^{-1}$, temperatura de $26 \pm 1^{\circ} \mathrm{C}$, permanecendo nessas condições durante 120 dias.

O delineamento estatístico utilizado foi o inteiramente casualizado com quatro repetições, sendo cada parcela constituída por 4 tubos de ensaio contendo uma planta por tubo. Avaliaram-se os explantes após 120 dias da instalação do experimento, observando-se a quantidade dos responsivos (explantes que emitiram pelo menos uma brotação), número e tamanho dos brotos formados, ocorrência de raízes e de intumescimento e calogênese.

\section{RESULTADOS E DISCUSSÃO}

Verificou-se que, pelos resultados das análises estatísticas realizadas para os parâmetros analisados neste experimento, houve interação entre os diferentes meios de cultura e as concentrações adotadas para todas as características.

Pela avaliação do número de explantes responsivos, observou-se que houve poucas respostas quando esses foram mantidos na concentração mais baixa dos meios de cultura $(50 \%)$, demonstrando que a presença de nutrientes oferecidos por um meio mais rico é fundamental para estimular o desenvolvimento da brotação (Figura 1A).

Comparando os meios de cultura testados, observou-se superioridade do meio MS sobre o Knudson, efeito esse atribuído à maior concentração de nutrientes apresentada pelo MS. Explantes cultivados nesse meio nas concentrações 100 e $150 \%$ apresentaram 25 e $43,75 \%$ respectivamente de explantes responsivos, enquanto, no meio Knudson, nas mesmas concentrações, ocorreram 12,5 e $25 \%$, respectivamente, de explantes responsivos. Não houve diferença significativa entre as diferentes concentrações do meio Knudson e do MS (Figura 1B e C).

A formação de brotações também foi influenciada pelo tipo de meio utilizado. O número médio de brotos formados no meio MS foi mais elevado em relação ao Knudson, com 0,52 e 0,125 brotos por explante respectivamente (Figura 2A). Para esse parâmetro, não houve diferença entre as concentrações utilizadas do meio Knudson (Figura 2B). Para o MS, as concentrações de 100 e $150 \%$ promoveram a formação de maior número de brotos, sem, no entanto, apresentar diferenças significativas entre si, em valores superiores aos resultados dos explantes cultivados em 50\%, conforme demonstrado na Figura 2C.

A quantidade de nutrientes do meio de cultura pareceu influenciar o número de brotações emitidas por Alcantarea imperialis, pois, em meio Knudson, mais pobre em nutrientes, conforme já descrito por GEORGE (1996), o número médio de brotações emitidas foi bastante inferior, em comparação ao MS. A mesma observação foi feita quando se utilizou $50 \%$ do meio MS.

A altura média de brotos formados in vitro apresentou comportamento semelhante ao observado para o número de brotações, ocorrendo média de $0,2 \mathrm{~cm}$ para
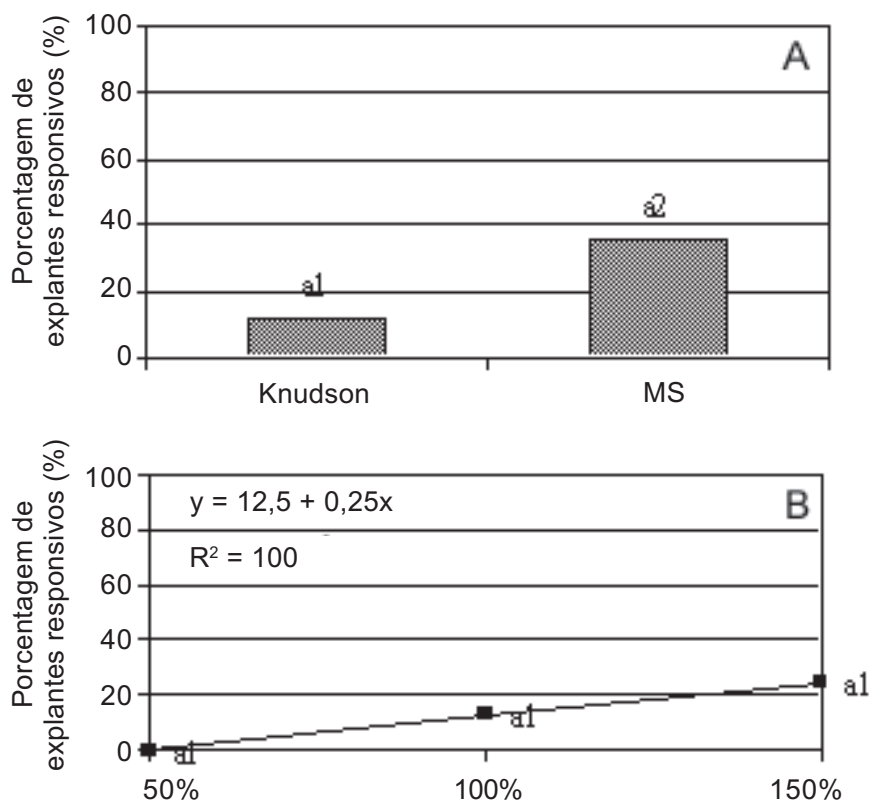

Concentrações do meio Knudson (\%)

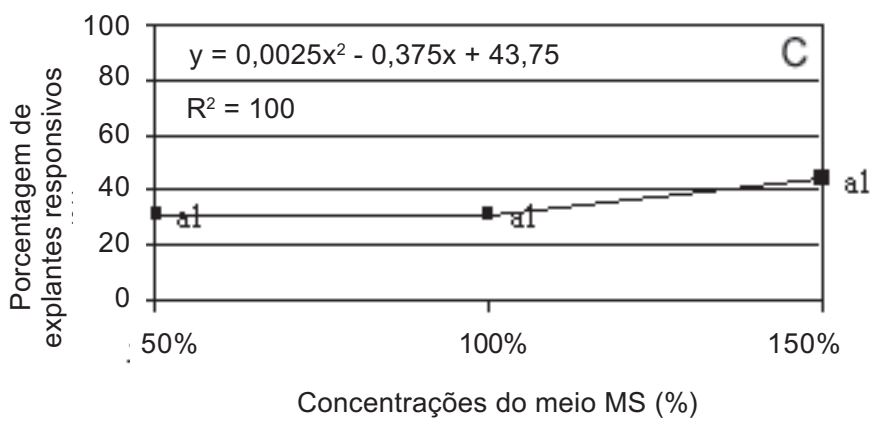

Figura 1. Porcentagem de explantes responsivos de Alcantarea imperialis: A- comparação entre os meios de cultura; B- comportamento em diferentes concentrações do meio Knudson; C- comportamento em diferentes concentrações do meio MS. 
os cultivados no meio Knudson e 1,2 $\mathrm{cm}$ para os do MS (Figura 3A). Entre as diferentes concentrações de cada meio, não houve diferença entre as alturas dos brotos formados no meio Knudson, enquanto no MS as concentrações 100 e $150 \%$ proporcionaram maior altura de brotos, 1,7 e 1,4 cm respectivamente, sendo superiores aos cultivados na concentração 50\% (Figura 3B e C). O baixo desempenho dessa espécie, quando cultivada em Knudson (CÂNDIDO, 1996) pode ser atribuído à menor disponibilidade de nutrientes desse meio (CALDAS et al., 1998).

O intumescimento é um tipo de formação que parece preceder a emissão de brotações. Nos explantes cultivados em meio Knudson, cerca de 25\% apresenta-
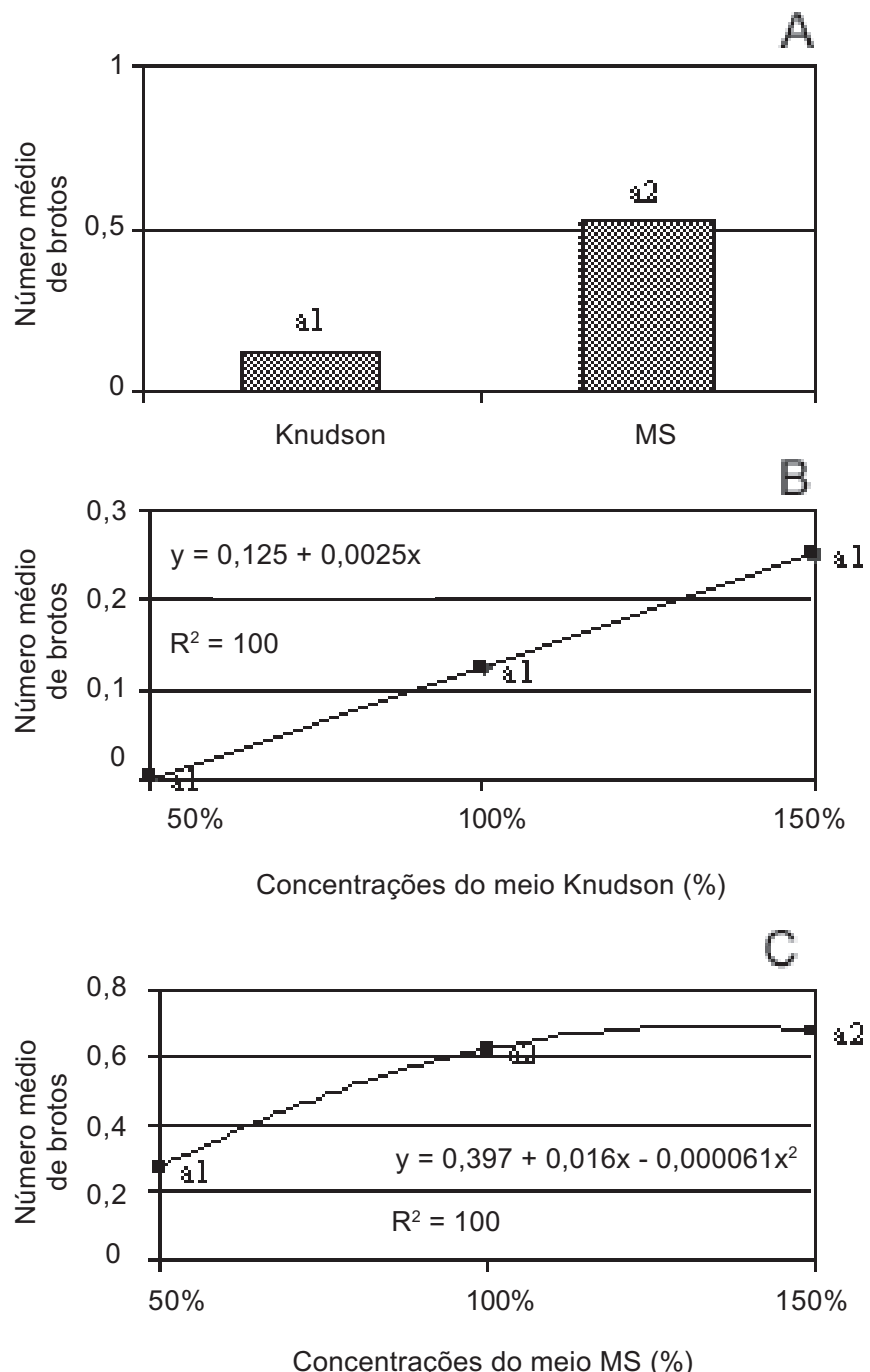

Figura 2. Número médio de brotos formados em explantes de Alcantarea imperialis cultivados in vitro: A- comparação entre os meios de cultura; B- comportamento em diferentes concentrações do meio Knudson e C- comportamento em diferentes concentrações do meio MS. ram intumescimento, ao passo que no MS esse ocorreu em torno de 50\% (Figura 4).

O intumescimento em explantes de bromélias parece ser uma reação comum das plantas dessa família, já tendo sido relatada por NAVES \& PINTO (1996) e CARNEIRO (1997), os quais registraram a presença de protuberâncias nos seus explantes. Trata-se de um crescimento na base do explante, diferindo da formação de calos, por apresentar um aspecto liso, como de um bulbo, mas sem interferência na formação de brotos.

Não houve formação de raízes, provavelmente em vista da ausência de auxinas nesses meios de cultura.
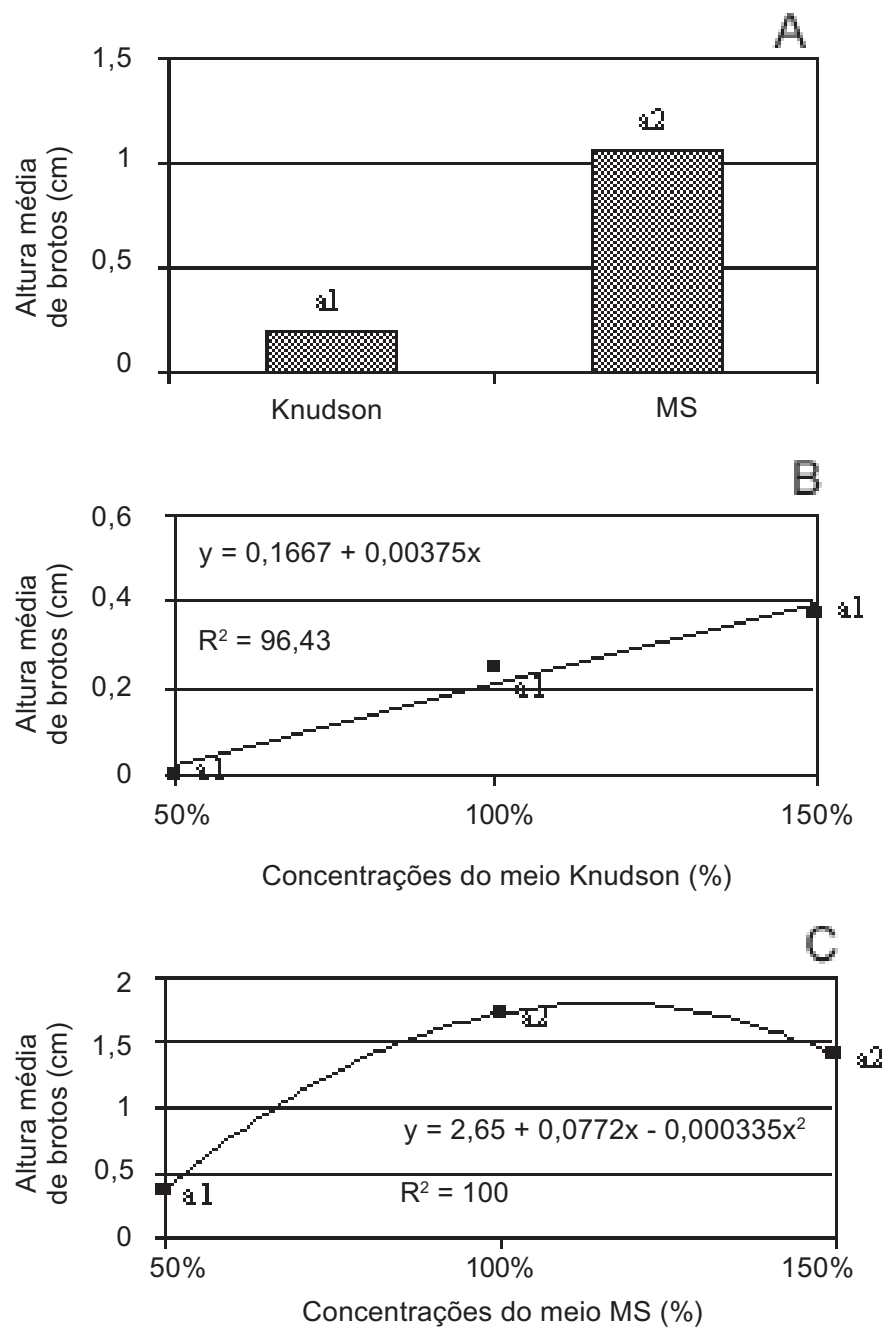

Figura 3. Altura média de brotos de Alcantarea imperialis formados em explantes cultivados em diferentes meio de cultura: A- comparação entre os meios de cultura; Bcomportamento em diferentes concentrações do meio Knudson e C-comportamento em diferentes concentrações do meio MS. 


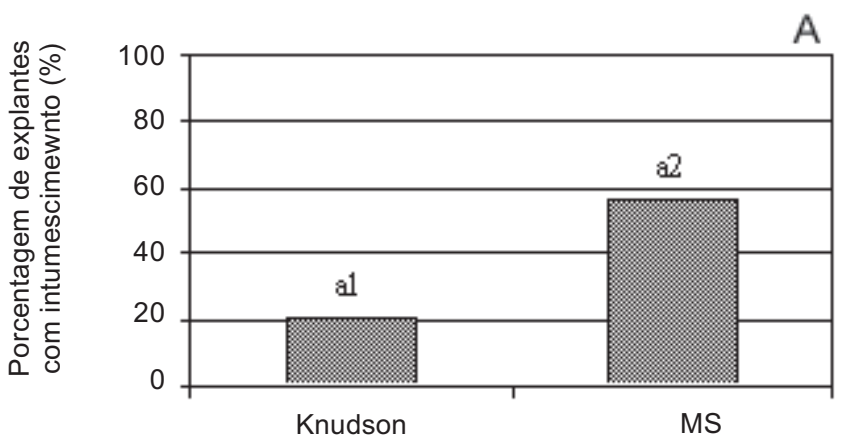

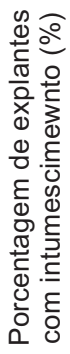

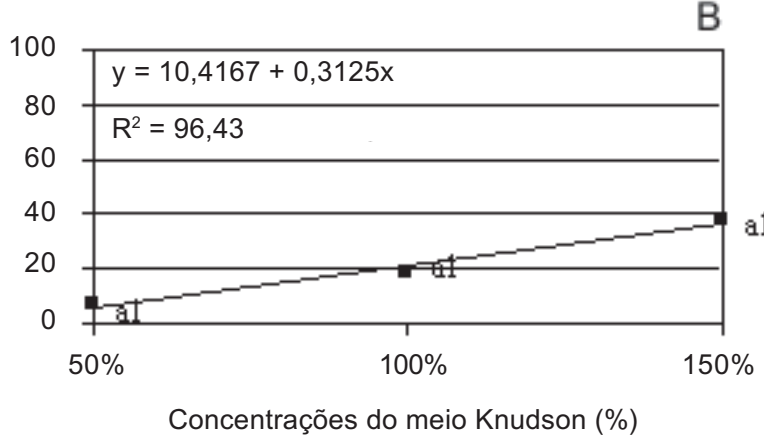

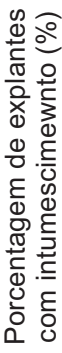

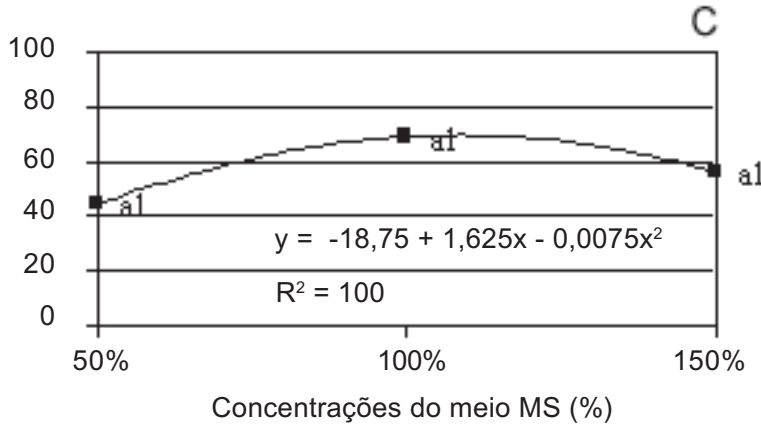

Figura 4. Porcentagem de explantes de Alcantarea imperialis com presença de intumecimento: A- comparação entre os meios de cultura; B- comportamento em diferentes concentrações do meio Knudson e C- comportamento em diferentes concentrações do meio MS.

Houve uma tendência de maior crescimento do explante inicial quando cultivado no meio MS, chegando à média de 4,4 $\mathrm{cm}$ de comprimento, ao passo que no Knudson, a média foi de 1,6 cm (Figura 5). Ao contrário dos outros parâmetros, a diferença no tamanho do explante inicial foi significativa entre as diferentes concentrações testadas dos meios de cultura, crescendo proporcionalmente à medida que se aumentaram as concentrações dos meios, como ilustra a Figura 5 (B e C).

Observou-se que o meio MS, em maiores concentrações, proporcionou maior desenvolvimento do explante, assim como também os brotos formados nas gemas laterais apresentaram maior tamanho.
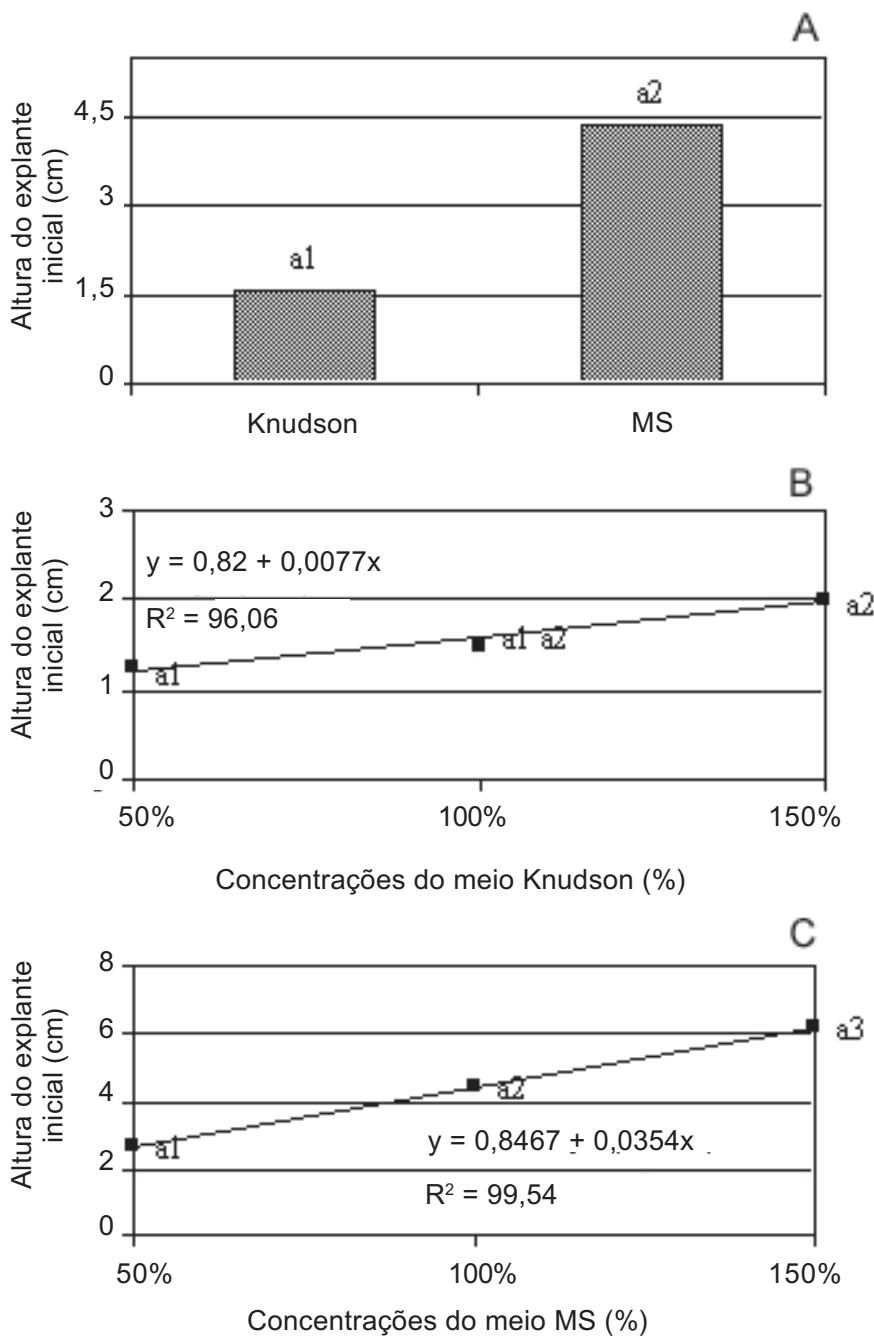

Figura 5. Altura média do explante inicial de Alcantarea imperialis em cultivo in vitro em diferentes meio de cultura: A- comparação entre os meios de cultura; B- comportamento em diferentes concentrações do meio Knudson e C- comportamento em diferentes concentrações do meio MS.

\section{CONCLUSÕES}

1. O meio MS, em sua concentração original, proporcionou melhores resultados, ocorrendo melhor desenvolvimento dos explantes de Alcantarea imperialis cultivados in vitro.

2. As diferentes concentrações do meio Knudson não diferiram estatisticamente entre si em nenhum parâmetro analisado.

3. As concentrações mais elevadas de MS proporcionaram maior número de brotos. 


\section{REFERÊNCIAS BIBLIOGRÁFICAS}

CALDAS, L.S.; HARIDASAN, P. \& FERREIRA, M.E. Cultura de tecidos e transformação genética de plantas. Brasília: EMBRAPA, 1998, v.1, p. 103.

CÂNDIDO, M.S.D. Cultivando Chrypthantus. Bromélia, Rio de Janeiro, v.3, n.1, p. 33-37, 1996.

CARNEIRO, L.A. Controle da morfogênese in vitro de três espécies de bromélias endêmicas do Sudeste brasileiro. Piracicaba: ESALQ, 1997. 87p. (Tese - Doutorado em Agronomia.)

DIJCK, R.V.; PROFT, M. \& GREEF, J. Role of ethylene and cytokinins in the initiation of lateral shoot growth in bromeliads. Plant Physiology, v.86, p. 836-840, 1988.

DOSOLTO, R. Bromélias semeadas, bromélias preservadas. Entrevistador: Rose Aielo Blanco. Jardim de flores. São Paulo, 2001. Disponivel em: <http://www. jardimde flores.com.br/ ECOLOGIA/bromelia1.html\#topo1>. Acesso em: 04 set. 2001.

GEORGE, E.F. Plant propagation by tissue culture, Part 1 - The technology. 2.ed. Edington: Exegetics Limited, 1996. 1574p.

LEME, E.M.C. \& MARIGO, L. C. Bromélias na natureza, Rio de Janeiro, Marigo comunicação visual. 1993. 183p.

MELO, T.B. Bromélias no paisagismo. Bromélia, Rio de Janeiro, v.3, n.1, p.3-7, 1996.

MERCIER, H. \& KERBAUY, G.B. In vitro multiplication of Vriesea fosteriana. Plant Cell, Tissue and Organ Culture, Dordrecht, v.30, p.247-249, 1992.

MERCIER, H. \& KERBAUY, G.B. In vitro culture of Vriesea hieroglyphica, an endangered bromeliad from the Brazilian Atlantic Forest. Journal of the Bromeliad Society, Los Angeles, v.44, p.120-124, 1994.

MERCIER, H. \& KERBAUY, G.B. Importance of tissue culture tecnique for conservation of endagered Brazilian bromeliads from Atlantic rain forest canopy.Selbyana, Sarasota, v. 16, n. 2, p. 147-149, 1995.

MURASHIGE, T. \& SKOOG, F.A. A revised medium for rapid growth and biossays with tabacco tissue culture. Physiologia Plantarum, Copenhagen, v. 15, p.473497, 1962.

NAVES, V. C. \& PINTO, J. E. B. P. Aplicação do Thidiazuron na indução de brotações em bromeliáceas. In: CONGRESSO BRASILEIRO DE INICIAÇÃO CIENTÍFICA EM CIÊNCIAS AGRÁRIAS, 14., Santa Maria, 1996. Anais... Santa Maria, UFSM, 1996. p.109.

OLIVEIRA. M.G.N.; ROCHA, C.F.D. \& BANGNALL, T. A comunidade animal associada à bromélia-tanque Neoregelia cruenta (R. Graham) L.B. Smith. Bromélia, Rio de Janeiro, v.1, n.1, p.22-29, 1994.

NUNES, J.V.C. \& FORZZA, R.C. Bromélias. Projeto: Inventário dos recursos naturais da Mata Atlântica, São Paulo, v.1, n.1, 1998. Disponível em: <http:// www.unicamp.br/ nipe/rbma/bromain.htm $>$. Acesso em: 04 set. 2001

PIERIK, R.L.M.; SPRENKLENS, P. A. Micropropagation of Tillandsia cyanea. Journal of the Bromelied Society, Los Angeles, v.38, n.2, p.9-12. 1988.

PIERIK, R.L.M. \& STEEGMANS, H.H.M. \& HENDRIKS, J. The influence of naphthaleneacetic acid on the growth of in vitro-cultivated seedling of Bromeliaceae. Scientia Horticulturae, Amsterdam, v. 24, p. 193-199,1984.

RAUH, W. The bromeliad lexicon. Blandford, London, 1990. $215 \mathrm{p}$.

TOMBOLATO, A.F.C.; TAKEBAYASHI, S.S.G.; COSTA, A.M.M. \& QUIRINO, E.A. Cultura in vitro da Bromélia. O Agronômico, Campinas, v.43, n.2/3, p. 77-78, 1991.

ZORNING, R.K. Micropropagação de bromélias. Bromélia, Rio de Janeiro, v.3, n.3, p.3-8, 1996. 